\title{
Patriotic education of future teachers in a university
}

\author{
Irina Khlyzova ${ }^{1, *}$, Lyudmila Illarionova $^{1}$ and Peter Khromenkov ${ }^{1}$ \\ ${ }^{1}$ Moscow Region State University, 105005, Radio str, 10A, Moscow, Russia
}

\begin{abstract}
The purpose of the study: to identify the pedagogical conditions for patriotic education of future teachers in a university. Object of study: educational system of a university. Subject of research: patriotic education of future teachers in a university. In accordance with the purpose of the study, the following tasks were set: to identify the main theoretical aspects of patriotic education of future teachers and its features; to characterize the forms, methods and means conducive to patriotic education of future teachers; to identify pedagogical conditions for patriotic education of future teachers; to develop components for patriotic education of future teachers on the basis of the analysis of scientific literature.In this study, the following research methods were used: analysis, synthesis, analogy, abstraction, the study of psychological and pedagogical literature, questionnaires. The theoretical significance of the work is to comprehend and theoretically revise the problems devoted to patriotic education of future teachers in a university. The essence of patriotic education of young people in modern conditions is presented, which is understood as the formation of a patriotic consciousness (responsible attitude to nature, to oneself, as a whole with nature and society, to the world around and to the Motherland; focus on the value aspect of the formation of patriotism); patriotic behavior (activation of the activity aspect of future teachers), and patriotic feelings. The components of patriotic education are presented: motivational, cognitive, emotional, and activity components.It is concluded that the relevance of this problem is quite acute, and it is necessary to strengthen attention on patriotic education of youth. A survey conducted to study the level of patriotism of future teachers showed that negative qualities such as negativity towards modern political systems; negative attitude to their country; the desire of youth to leave Russia and live in Europe and the USA; highly developed individualism, egoism; disrespect for the older generation prevail in the minds of young people.
\end{abstract}

\section{Introduction}

The problem of patriotic education of youth is an urgent problem in modern Russian society. Patriotism is one of the basic values of national culture and a means of developing a value attitude to the homeland, society, family, their traditions, lifestyle, and folk art. It acts as one of the criteria for assessing the personality education. Theorists and practitioners

\footnotetext{
*Corresponding author: hlizova_iv@mail.ru
} 
in various fields are trying to solve it today at the federal, municipal, regional levels. The decline of spiritual and moral values, the lack of patriotic feelings among young people are alarming features of the current situation in the Russian Federation. This situation entails the need to fulfill a social order to update the upbringing content in solving this problem. But it should be noted that many factors influence the results of the patriotic education of the younger generation, and the teacher plays the leading role in its organization. Only student-future teacher, educator who has mastered patriotic values can educate a true patriot [12].

The data of many analytical reports, scientific analyzes, and sociological studies testify to the problem of patriotic education $[1,4,5,6,7,13]$.

In recent years, negative processes have led to the fact that the majority of the population, especially young people, as it turned out, have lost basic values or they were destroyed: selflessness, patriotism, willingness to exploit, morality, nobility, faith in goodness, desire for honesty, desire to pursue state interests, etc. In most cases, young people have lost such feelings as: a duty to parents, family, friends, society, and the homeland.

Considering the reasons for such a change in the minds of young people, we came to the conclusion that this is the result of changes in the Russian Federation that occurred in the 90 s of the last century, when the old educational system aimed at educating a collectivist, a person who thinks about the welfare of the whole people, and not only about himself, was broken, and a new one was not built. Or, in other words, an Americanized system of education has been imposed, where the main thing is individualism, striving not for the common good, but for one's own, developed egoism, negative attitude to everything around, if this does not concern one's own interests.

Over the years of socio-political formations, a generation of young people has grown up who is not familiar with the best patriotic values, with the values of national unity for the achievement of a common goal.

The centuries-old history of the Russian people suggests that it is impossible to create a strong country without patriotism, it is impossible to instill in people a desire to fulfill their civic duty and respect for the law.

The problem of patriotic education of young people, including future teachers, is relevant in modern society and has deep roots in history. The concept of patriotism is characterized by variability, diversity. This is largely due to the complex nature of this phenomenon, the multidimensional nature of its content and the variety of forms of manifestation. In addition, the problem of patriotic education of youth is considered by different researchers in different conditions, depending on various fields of knowledge, personal civic position, attitude to their homeland, etc.

Nowadays, such goals of patriotic education of youth as the upbringing of a sense of patriotism; development and expansion of knowledge about the history and culture of the Russian Federation and the native land; the formation of the ability to understand events and phenomena of reality in the relationship of the past, present and future; the formation of a multifaceted Russian citizen in cultural, moral and physical aspects; the development of interest and respect for the culture and history of various peoples of the Russian Federation, the development of a sense of pride in Russia and state symbols prevail.

Achieving these goals becomes possible by solving the following tasks: to form a conscious attitude to the native land, its past, present and future on the basis of historical achievements; to develop civic spirit and national identity of youth; create conditions for youth to realize their own civil position through the activities of youth self-government bodies; to replenish the knowledge of history and cultural traditions of the Russian Federation; to develop a sense of pride among young people for the heroic deeds of the 
past; methodological support for the functioning of the system of patriotic education of youth, etc.

Education is a device of interaction between generations, which ensures the entry of the subject into society and the further formation of their active subjects in the historical process.

In various historical eras, depending on the socio-economic conditions of society and the prevailing ideology in it, various aspects were invested in patriotic education.

Pedagogical research on the problem of patriotic education is varied and numerous. The studies reveal both theoretical and methodological aspects (the content of the concept of "patriotism", its characteristics, means of formation, etc.) and applied ones (various areas of patriotic education: military-patriotic, education on the labor and military traditions of the people, the relationship of patriotic, aesthetic, and mental education of youth, etc.). Great importance was given to patriotic education of young people by I.F. Isaev, N.K. Krupskaya, A.S. Makarenko, A.M. Novikov, N.I. Pirogov, V.A. Sukhomlinsky, V. A. Slastenin, K. D. Ushinsky, etc.

Of particular importance in the study of questions of patriotic education are the works of V. Sukhomlinsky He pointed to the difficulty of educating patriotism, explaining this by the fact that in everyday life we do not encounter a quantity by which patriotism could be measured. Love for the homeland becomes a fortitude when a person has the images in his mind that are related to his native homeland, language, when there is a sense of pride that this is all your homeland [8].

G. Efremova considers patriotism as love for your own country, devotion to your people and responsibility to them, readiness for any sacrifices and exploits in the name of the interests of your homeland; the highest manifestation of the human spirit [3].

I.F. Kharlamov understands patriotism as a combination of behavior and moral feelings, including active work for the good of the Motherland, love for the homeland, respect for historical monuments and traditions of the Motherland, affection and love for the homeland, following and multiplying the working traditions of the people, a desire to strengthen honor and the dignity of the motherland, the desire and ability to protect it, courage and selflessness, friendship and brotherhood of nations, intolerance of racial and national hostility, respect for the customs and culture of other countries and people, the desire for cooperation with them [9].

At the end of the twentieth century, instead of fostering collectivism, youth began to strengthen the idea of fostering individualism, selfishness, the value of material wealth, and instead of patriotic education, ideas of disrespectful attitude to Russian history and disrespectful attitude to their people began to be promoted. This situation has led to the fact that the concepts of "patriotism", "patriot" take a negative meaning. But for the older generation brought up in Soviet times, it retained its original positive significance - a sense of pride in their homeland, a sense of the importance of the historical development of Russia, pride in scientific discoveries. Having lost patriotism, the associated national pride and dignity, we lose ourselves as a people capable of great achievements.

From our point of view, a partial loss of patriotism in the Russian Federation occurs among young people because of the following reasons:

- the result of changes in the Russian Federation in the 90s of the last century, when the old educational system aimed at educating the collectivist, a person who thinks about the welfare of the whole people, and not just about himself, was broken, and the new educational system was not built.

- the imposition of Americanized values of individualism, striving not for the common good, but for their own, developed egoism;

- craving for material good, the prevalence of the material above the spiritual one;

- craving for an idle lifestyle, for entertainment; 
- deterioration of physical and mental health;

- moral decline among young people;

- decrease in intellectual potential;

- decrease in the role of youth in society;

- decrease in spirituality;

- predominance of negativity in behavior.

K.D. Ushinsky also said that the future of the country depends on the education of young people. Therefore, if we want to preserve our country, to exalt the greatness of the Motherland, it is necessary to radically revise our attitude to the education of students.

In this regard, when organizing the educational process aimed at the formation of patriotic education, a systematic and deep enrichment of all aspects of educational work with patriotic content is necessary, which is a necessary condition for the education of a true patriot.

\section{Materials and methods}

Nowadays, the problem of patriotic education of young people is one of their main problems. The formation of patriotism is announced in normative legal acts, in state programs, publications and projects. So, in 2016, the Government program "Patriotic education of citizens of the Russian Federation for 2016-2020" was adopted by the Decree of the Government of the Russian Federation dated December 30, 2015. The number of organizations of supplementary education that contribute to the formation of patriotic education is increasing, which gradually increases the level of patriotism among young people.

Organizations for military-sports education are being created in the subjects of the Russian Federation.

In universities, programs are being implemented to prepare students for military service. According to research, young citizens who participate in activities for patriotic education or pre-conscription training of youth make up $22.5 \%$ of the total number of citizens of the Russian Federation. But modern studies show that there is a decline in patriotism among modern youth.

From our point of view, the essence of the patriotic education of young people in modern conditions can be understood as the formation of a patriotic consciousness (responsible attitude to nature, to oneself, as a whole with nature and society, to the world and the homeland; focus on the value aspect of the formation of patriotism); patriotic behavior (activation of the activity aspect of future teachers) and patriotic feelings.

In order to study the level of patriotism in 2nd year students of Moscow Region State University, in the process of scientific research in the framework of teaching the discipline "Pedagogy", the survey was conducted among future teachers of the specialty 44.03.05 "Pedagogical education", profiles "Russian language and literature", "Russian language and foreign English language", "Russian language and world art culture".

\section{Results}

The questionnaire consisted of several questions. And the answers of future teachers make you think (Figure 1.).

Question 1: "Do you consider yourself a patriot of Russia?" - 55\% said no.

Question 2: "In which country would you like to live?" - 61\% said they would like to live in Europe and the United States. 
Question 3: "What are the reasons for leaving for another country?" - 60\% answered that the reason is the unstable economic situation in the country.

Question 4: "What events does evoke patriotism in you?" - 45\% replied that these are events such as "Immortal Regiment" on Victory Day; 15\% - watching documentaries and feature films about the Second World War.

Question 5: “Are you proud of the achievements of your country?" - 35\% said yes.

Question 6: "What achievements of Russia are you proud of?" - 75\% said they were proud of the achievements of scientists who made world discoveries: A.S. Popov, K.E. Tsiolkovsky, I.V. Kurchatov, S.P. Korolev, and victory in the Second World War.

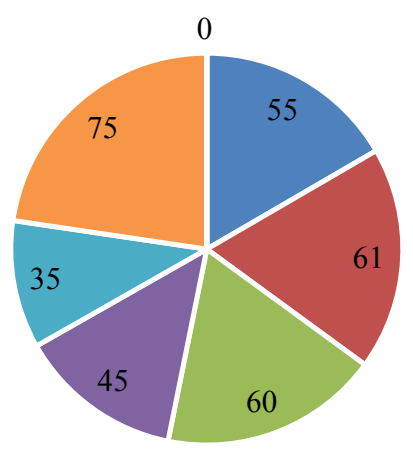

-Question 1 - Question 2 - Question 3 - Question 4 - Question 5 - Question 6 -

Fig. 1. Questionnaire to identify the main aspects of patriotism among future teachers of the $2 \mathrm{~d}$ year of study.

A survey was also conducted to study the concept of patriotism among future teachers of the $2 \mathrm{~d}$ year of study (Figure 2). To the question "What do you think is patriotism?" - 51\% replied that it is pride in their country; $18 \%$ replied that it is love for the motherland; $15 \%$ replied that it is a service to the motherland; $12 \%$ replied that it is self-sacrifice for the sake of the motherland; $16 \%$ replied that it is loyalty to Russia and its culture (Figure 2).

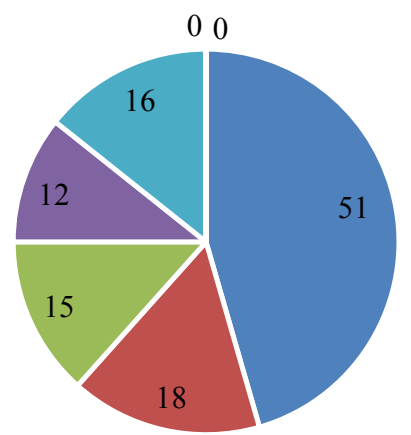

- Pride in your country

- Love to the Motherland

- Service to the Motherland

- Sacrifice for the sake of the Motherland

Fig. 2. The study of the concept of patriotism in future teachers of the $2 \mathrm{~d}$ year of study. 
Based on the survey data of future teachers, we can conclude that the relevance of this problem is quite acute, and it is necessary to strengthen attention on the patriotic education of young people. A survey conducted to study the level of patriotism of future teachers showed that negative qualities such as negativity towards modern political systems; negative attitude to their state; the desire of young people to leave Russia for Europe and the United States not only to study, but also for permanent residence; highly developed individualism, egoism, when a person thinks not about the common good, but only about his own well-being; disrespect for the older generation, low level of education prevail in the minds of young people.

To educate patriotism among future teachers, a model of patriotic education of future teachers in a university was developed. In the framework of this model, students are introduced to the values of the modern world, including patriotism, love of the motherland, etc.

Patriotic education is interconnected with all aspects of the education process. It can be represented as a process of socialization, which ensures the appropriation by an individual of social experience, as a result of which a person acquires important values in society, masters the ways of socially adapted behavior.

The core of the model of patriotic education of future teachers in a university is the pedagogical conditions:

- formation of a patriotic consciousness: a responsible attitude to nature, to oneself, as a whole with nature and society, to the world and the homeland (focus on the value aspect of the formation of patriotism);

- formation of patriotic behavior (activation of the activity aspect of future teachers);

- formation of patriotic feelings.

The functioning of the system of patriotic education of future teachers in a university is associated with the implementation of a special series of pedagogical tasks, for the solution of which various forms, methods, means, methods and techniques of teaching are used. Forms and methods of educating patriotism are implemented through various activities that are carried out systematically, with a certain cyclicality, in accordance with scientifically sound pedagogical conditions that contribute to the education of patriotism among future teachers in a university. The most promising in terms of the educating of patriotism among future teachers in a university is the use of complex combined integrated forms of education that optimally combine both general and specific of its content.

A holistic and open educational system has a huge number of connections and relationships with the surrounding social environment, which ensures its functioning. The expansion of educational space is carried out in this system through relations with institutions and organizations.

The core of the educational system is the formation of a patriotic consciousness (responsible attitude to nature, to oneself, as a whole with nature and society, to the world and the Motherland); the formation of patriotic behavior (activation of the activity aspect of future teachers); and the formation of patriotic feelings.

\section{Discussion}

From our point of view, the values of patriotism can be assimilated by students if some ideas are embodied:

- the idea of harmonizing the values of generations,

- the idea of acquiring skills of conscious choice and understanding of personal responsibility,

- the idea of optimally organized student activities. 
For the formation of patriotism among young people, it is important to form the components of patriotism.

These components, from our point of view, are: motivational, cognitive, emotional and activity components.

Let's consider the system of educational work in the university on the formation of each of these components.

One of the main roles in the process of educating patriotism among young people is played by the formation and development of the motivational sphere of the individual. The formation of the motivational sphere of the personality is realized in the process of various forms of extracurricular work by creating situations in which future teachers would experience feelings of love and pride in the Motherland. The essence of educational work, from our point of view, should consist in creating internal contradictions that contribute to the emergence of patriotism among young people. Internal contradictions arise if a person experiences a dissonance between what he is at the moment and what he should be like under the influence of external influences or internal impulses; between the achieved and the necessary level of personal development.

The cognitive component of patriotism includes a deep understanding of the essence of these moral qualities and how they are expressed in various types of activity and behavior of the subject. This component comprehensively applies the basic features of training sessions. Many opportunities for this exist in extracurricular activities: conversations on patriotic topics, essays, concerts, literary evenings, organization of search activities, assistance to veterans of the Second World War, collective and creative affairs on patriotic themes, etc. However, it is very important that this work is not carried out superficially, but that it promotes the development of such patriotic personality traits among young people as loyalty to the Motherland, courage, honor, dignity, etc. It is necessary that this work would awaken a sense of attachment to the Motherland among young people, accompanied by colorful emotional and aesthetic experiences.

The native language has a huge influence on the emotional component of patriotism. Stability and the formation of moral consciousness on issues of patriotism is achieved only if the knowledge of young people on these issues takes on the character of personal views and beliefs, and acts as motives and attitudes. For the development of patriotic views and beliefs, it is important that the fund of knowledge about the essence and methods of manifestation of these qualities not only be acquired by the subjects, but acquire a personal meaning, go through their experiences and guide their activities and behavior [2].

Educational work in this case should not only has bright and emotionally elevated character, but also differ in the scale of factual material and be filled with brilliant examples of patriotic courage and braveness.

The active component of patriotism includes the intense activity of youth in the field of patriotism. An important means for the formation of youth's ability to engage in activities in the field of patriotism is the skillful inclusion of youth in various types of practical activities and the formation of skills and patriotic behavior. This includes various types of patriotic activities: meetings with veterans of the Second World War; care for the monuments to heroes who died in the Second World War; measures to protect and preserve the environment; hiking in places of military glory; excursions; local history activity; historical expeditions; ethnic expeditions; celebration of historically important dates; meetings with representatives of various nations and national entities, etc.

If this activity is informative and regular in nature and is combined with the development of the motivational, cognitive, emotional, and active components of patriotism among young people, it undoubtedly contributes to the consolidation of patriotic views and beliefs. 
For the development of patriotic views and beliefs among young people, the creation of pedagogical situations, which would include elements of debate, contradictions of opinions, upholding their judgments, is of great importance. As a result, subjects begin to develop their own point of view, upholding their internal positions. The main thing is not to forget that in order to strengthen views and beliefs, it is very important that a person finds himself in such an emotional state that would leave an imprint in the need-motivational sphere and become an irresistible internal force of his life ideals and aspirations.

We are talking about patriotic education of young people, the content of educational work, the creation of pedagogical conditions that contribute to the emergence of internal contradictions in subjects of education that would stimulate them to develop patriotic qualities. Based on the foregoing, we can observe that the various forms, methods, and means of the educational process used stimulate the subjects of education to actively participate in practical and cognitive activities and promote the development of patriotism.

\section{Conclusions}

Thus, according to the results of the conducted work, it was revealed that the work on the patriotic education of youth includes a whole range of tasks: nurturing youth with a sense of love for their native land; formation of interest in Russian traditions and crafts; building knowledge of human rights; development of a sense of pride in the achievements of the Motherland; formation of tolerance towards other people, nations, traditions and religions. Based on the survey data of future teachers, it was concluded that the relevance of this problem is quite acute, and it is necessary to strengthen attention on the patriotic education of young people. A survey conducted to study the level of patriotism of future teachers showed that negative qualities such as negativity towards modern political systems; negative attitude to their country; the desire of youth to leave Russia and live in Europe and the USA; highly developed individualism, egoism; disrespect for the older generation prevail in the minds of young people.

In order to educate patriotism in future teachers in the university, it is important to formulate the following components of patriotism: motivational, cognitive, emotional, and activity components. The following conditions are the core of the educational patriotic system: the formation of a patriotic consciousness (responsible attitude to nature, to oneself, as a whole with nature and society, to the world and the Motherland); the formation of patriotic behavior (activation of the activity aspect of future teachers); and the formation of patriotic feelings.

In the modern world, in a rapidly changing situation in the country, patriotic education of youth is a prerequisite for the development of the country and considerable attention should be paid to the problems of education of youth.

\section{References}

1. E.I. Artamonova, Pedagogical Education and Science 5, 7 (2018) ISSN 2072-2524

2. N.A. Gorlova, Scientific and theoretical journal of the Russian Academy of Education "Pedagogy" 1(84), 35 (2020)

3. G. Efremova, Education of schoolchildren 8, 17 (2013)

4. L.P. Illarionova, World of science, culture, education: scientific journal 6(73), 62 (2018)

5. V.A. Kobylyansky, Pedagogy 5, 52 (2015)

6. V.I. Prikhodko, Youth and society 2, 53 (2015) 
7. E.A. Savchenko, Anthropocultural approach to the educational activities of a teacher: dissertation of Doctor of pedagogical sciences (Moscow, Moscow State University for Humanities named after M.A. Sholokhov, 2014)

8. V.A. Sukhomlinsky, Selected pedagogical essays: in 3 volumes (M., Pedagogy, 1979)

9. I.F. Kharlamov, Pedagogy: Textbook (M., Gardariki, 2003)

10. I.V. Khlyzova, Materials of the International scientific and practical conference (M., MANPO, Yaroslavl, Remder, 2019)

11. I.V. Khlyzova, Values and meanings 4, 169 (2019)

12. P.A. Khromenkov, Modern problems of science and education 1 (2019) http://www.science-education.ru/ru/article/view?id=28574

13. T.A. Yuzefavichus, Pedagogical education and science 6, 106 (2016) 